\title{
Investigation of nutrients properties of meat pastes using vegetative raw materials
}

\section{Oksana Moskaliuk ${ }^{1}$, Oleksandra Haschuk ${ }^{1}$, Liudmyla Peshuk ${ }^{1}$, Liudmyla Sineok ${ }^{2}$, Oleg Galenko ${ }^{1}$}

1 - National University of Food Technologies, Kyiv, Ukraine

2 - Institute of Gerontology after D. F. Chebotareva NAMS of Ukraine, Kyiv, Ukraine

Keywords:

Meat

Pastes

Vegetative

Fatty acid

Transformability

\section{Article history: \\ Received 21.12.2017 \\ Received in revised \\ form 11.02.2018 \\ Accepted 29.06.2018}

\section{Corresponding \\ author:}

Oleg Galenko

E-mail:

galen@i.ua

DOI: $10.24263 / 2310-$

1008-2018-6-1-7

\section{Abstract}

Introduction. The researched meat pastes for healthpreventive nutrition using mushroom raw materials and phytocomplex of sprouted grains of cereal crops.

Materials and methods. The study of the fatty acid composition of the developed pates was carried out by chromatography of high resolution. To confirm the nutrients adequacy of the researched formulations of the "Mushroom" paste and the paste with the phyto-complex "CHOICE", studies were conducted digestibility in conditions in vitro of the Tetrahymena pyriformis ciliary infusoria in the Fuks-Rosenthal chamber. Clinical studies of the pastes with mushroom raw material were conducted with the participation of the elderly in the general-therapeutic department of the clinic.

Results and discussion. The method of chromatography of high-level ability has established the group fatty acid composition of the pastes using mushroom raw materials and phytocomplex of germinated grains of cereal cultures and found that the content of monounsaturated acids in developed paste is about $35 \%$ and saturated - only $23 \%$ in all investigated samples. Analyzing the content of PUFAs, it is important to note their stable high content in all four recipes, regardless of the type of ingredients added. However, the formula with mushroom raw material has the highest total PUFAs content $-41.92 \%$ and at the same time the highest content of essential linolenic acid $-1.55 \%$.

The results digestibility in conditions in vitro indicate that Mushroom Paste has a higher relative biological value and a better digestibility than the control sample more on $3.5 \%$, and the paste with the phyto-complex "CHOICE" more on $2.1 \%$.

According to the results of the research, the effectiveness and safety of the paste "Mushroom" has been determined and the possibility of eliminating vitamin $\mathrm{B}_{12}$ deficiency during use has been determined.

Conclusions. The analysis of the research results testifies to the nutrients adequacy of the researched pates with the use of mushrooms raw materials and phytocomplex of sprouted grains of cereals for health and health-preventive nutrition. 


\section{Introduction}

The ability to work, health and active creative longevity of a person is directly dependent on the way of his life and the nature of nutrition, which should be rational, balanced and to ensure the physiological needs of the organism. Currently, human life is very closely related to the impact of various unfavorable environmental factors, which leads to stress and certain negative changes in the body and health. Among them is also the lack of necessary nutrients: protein, trace elements, vitamins. In addition, various diseases, smoking and alcohol use also affect the absorption and metabolism of vitamins, especially vitamins $\mathrm{B}_{6}$ and $\mathrm{B}_{12}$. In order to enhance the immune functions of the body, science offers innovative ways. The growing interest in so-called "healthy food" necessitates the production of products that not only satisfy the physiological needs of the body in nutrients and energy, but also provide preventive and curative action. The principles of nutrition should consist in the use of products that are relatively easy to assimilate and diverse, also in terms of chemical composition and prophylactic orientation, it is possible to take into account the prevention or slowdown of the development of diseases. The development of technologies for the production of high-grade, nutritiously balanced products that provide adequate nutrition to the elderly should be a priority concept for the development of the food industry. Developing foods for special nutrition is a way through which you can change the composition of the product in such a way as to positively affect the health of a person, strengthening it by regulating certain metabolic processes in the body [1].

According to the results of the research of poultry meat and poultry products were developed for health and preventive nutrition "Mushroom" - with cooked oyster mushrooms - 15\%, "Special" - with mushroom biomass of oyster mushrooms- 3\% and with phytocomplex of sprouted grains of cereal crops $-15 \%$ [2].

Meat Pastes, where meat is the main ingredient, is in demand due to its high nutritional value, a pleasant special taste and a delicate consistency. Liver is added to the meat paste to enhance the biological value, providing a delicate taste and a rich color. The smearing consistency of paste is achieved by special methods of processing the raw materials and selecting the ingredients of the formulation. Traditional meat paste formulations are evaluated mainly for organoleptic parameters and energy value, without taking into account the product's balance on chemical composition.

Poultry meat is assimilated by $94-96 \%$, fatty tissue (5.2\%) is characterized by a high content of polyunsaturated fatty acids. The liver is rich in iron-containing proteins - ferrin and ferritin, which serve as a source of iron for the synthesis of hemoglobin. It contains nitrogenous extractives, as well as vitamins and minerals. It contains especially choline, biotin, vitamin A (50 $\mathrm{mg} \%), \mathrm{C}(25-40 \mathrm{mg} \%)$, niacin, and also includes all vitamins of group B. Given the chemical composition of the liver is widely used in therapeutic nutrition for anemia, radiation illness, general weakening and reduced hematopoiesis of the body.

The use of vegetable protein becomes topical for the domestic meat processing industry, which lacks the traditional raw material resources. In this regard, the role of products from natural plant materials, in particular fungi, is increasing. Mushroom proteins occupy an intermediate position between proteins of plant and animal origin. Mushrooms are also called "vegetable meat", they contain glycogen and do not have cholesterol, their taste resembles the taste of meat, due to the high content of glutamine amino acid. Mushrooms have a unique balanced composition of all the biologically valuable food components: proteins, fats, carbohydrates, vitamins, and trace elements. BAS mushrooms normalize appetite, increase immunity, lower cholesterol low density, reduce the risk of heart attack and prevent the onset of atherosclerosis, affect the development of memory and activate mental activity of man. Mushrooms have radioprotective properties. In the processing of fungi, there remains a significant number of non-standard and non-standard 
specimens that can be successfully used as protein-rich feedstocks. As a result of scientific research and on the basis of complex experimental research, the possibility of using cultured mushrooms in the recipes of meat pates was proved [2].

Germinated grains of cereal crops - a product that contains natural antioxidants, which is much more useful than synthetic drugs. The introduction of sprouted grains in minced meat products will enable to stimulate metabolism and hematopoiesis, increase immunity, compensate for vitamin and mineral deficiency, normalize the acid-base balance, help clear the body from slags and slow down aging processes. The enzymes formed in sprouted grains split complex substances (proteins, fats, carbohydrates) into simpler (amino acids, fatty acids, simple carbohydrates). When consuming meat products using sprouted grains, the human body spends less energy on digestion and assimilation of food. $[3,4,5,6]$.

\section{Materials and methods}

For the practical regulation of the biological value of developed pates, their group fatty acid composition was determined by high resolution chromatography method.

In order to confirm the nutrients adequacy of the developed meat pastes, the study of digestibility in conditions in vitro were conducted using the Tetrahymena pyriformis ciliary infusoria in the Fuks-Rosenthal chamber. Clinical studies were also conducted to determine the effectiveness and safety of products and the relationship between the level of vitamin $\mathrm{B}_{12}$ in the blood and the possibility of correcting it with the help of developed meat paste.

One way of examining the degree of digestion of proteins by proteolytic enzymes of the gastrointestinal tract, which determines the biological value of food products, is to conduct experiments on cell cultures, whose representatives are the simplest. The ciliary infusoria Tetrahymena pyriformis in the morphological aspect is a cell, and in the physiological - a holistic organism. In order to determine the digestibility in conditions in vitro developed pates in comparison with the control sample, the relative biological value was determined in accordance with the guidelines for the use of the Tetrachymena pyriformis ciliary infusoria. Unicellular organisms have much less enzyme systems than humans and are generally easier in structure. Infusoria (these are single cell eukaryotic organisms having a nucleus) can be considered as an integral biological sensor with certain parameters suitable for food bioassays.

To do this, from each sample, samples were taken and prepared,we prepared separately nutrient media and introduced into them samples of paste. Then we have grown a test cultures in the culture medium, cultivated at a temperature of $20-25^{\circ} \mathrm{C}$, then counting cells that had grown over four days of cultivation in the Fuchs-Rosenthal counting chamber.

By the number of cultured cells in the Fuchs-Rosenthal chamber, the relative biological value of the product was determined, which was determined by the ratio of cells grown on the investigated products to the number of infusions in the control case with casein. The experimental error was $0.3 \%$.

It was explained to patients about the peculiarity of the study and the nature of the product, after which each of them signed an informed consent to participate in this study.

In the study, we used a comprehensive survey that would reveal the effect of the proposed product on health indicators (liver, kidney, digestive and lipid metabolism), as well as an opportunity to find out the possibility of eliminating vitamin $\mathrm{B}_{12}$ deficiency. The proposed product (paste) was taken by patients during the entire period of stay in the hospital (21 days) by $50 \mathrm{~g}$ every other day. 


\section{Results and discussion}

Researched recipes of meat and poultry meat-based pastes for health and preventive nutrition: "Mushroom" - with cooked oyster mushrooms - 15\%, "Special" - with mushroom biomass of oyster mushrooms $-3 \%$ and with phytocomplex of sprouted grains of cereal crops $-15 \%$.

The study of the chemical composition of the developed pates showed that the nutritional value of new formulations meet the requirements that are put forward to this assortment group. Physicochemical indices showed that the developed pastes have a low mass fraction of fat, high protein content, which leads to a decrease in energy value [3, 4].

An analysis of the amino acids has shown that the prototype contains all the essential amino acids necessary. In polycomponent systems of developed pastes limiting amino acid is valine + isoleucine, which is typical of forcemeat with plant material [2, 4].

The biological value of fats is determined by the content of polyunsaturated fatty acids (PUFAs). For a person, the essential fatty acids are linoleic C 18:2 and linolenic C 18:3, which belong to essential nutrients. Lack of food intake of linoleic and linolenic acids causes a violation of the regulation of metabolic processes in cell membranes, as well as in the processes of energy formation in mitochondria. PUFAs help accelerate the exchange of cholesterol in the body, slow down the formation of low-density atherogenic lipoprotein, and reduce the synthesis of triglycerols. The external manifestation of PUFA deficiency is a change in the skin condition (dryness, peeling, eczema, hyperkeratosis), increased susceptibility to ultraviolet rays, the appearance of peptic ulcers in the stomach and duodenum, caries of the teeth, arthritis. Recent advances in science deeper reveal the functions of fats in the human body and determine the changes in the norms of their consumption with food [9].

For the practical regulation of the physiological value of developed pastes, their group fatty acids composition was established by the method of chromatography of high resolution. The fatty fraction of the developed pastes contains all groups of fatty acids, but their content is uneven (Table 1).

It was found that the addition of mushroom and vegetable raw materials does not cause fundamental changes in the content of certain fatty acids. It has been established that about $2 / 3$ of the total content of fatty acids is unsaturated, which is a positive factor in the balance of the diet.

In order to ensure the functional properties of developed pastes, it is important not only quantitative but also qualitative composition of fats, especially the content of polyunsaturated fatty acids with a definite placement of double bonds with cis configuration. The main biological indicators of the fatty acid composition of the studied pastes are given in Table 2 . 
Fatty acids composition of the studied pastes, $\%$ of the sum of fatty acids

Table 1

\begin{tabular}{|c|c|c|c|c|}
\hline \multirow[b]{2}{*}{ Fatty acids } & \multicolumn{4}{|c|}{ Samples } \\
\hline & Control & $\begin{array}{c}\text { No. 1 } \\
\text { "Mushroom" }\end{array}$ & $\begin{array}{c}\text { No. 2 } \\
\text { «Special» }\end{array}$ & $\begin{array}{l}\text { No. } 3 \text { phytocomplex } \\
\text { "CHOICE" }\end{array}$ \\
\hline C 8:0 & 0,01 & 0,01 & 0,01 & 0,01 \\
\hline C 10:0 Capric & 0,01 & 0,02 & 0,01 & 0,01 \\
\hline C 12:0 & 0,06 & 0,03 & 0,03 & 0,03 \\
\hline C 14:0 & 0,37 & 0,11 & 0,36 & 0,37 \\
\hline C 14:1 & 0,07 & 0,08 & 0,08 & 0,07 \\
\hline C 15:0 & 0,06 & 0,06 & 0,06 & 0,06 \\
\hline C 16:0 & 16,68 & 16,05 & 16,90 & 16,76 \\
\hline c9-C 16:1 & 0,31 & 0,47 & 0,32 & 0,30 \\
\hline c7-C 16:1 & 2,79 & 2,91 & 2,91 & 2,90 \\
\hline C 17:0 & 0,10 & 0,10 & 0,11 & 0,11 \\
\hline C $17: 1$ & 0,05 & 0,05 & 0,05 & 0,05 \\
\hline C 18:0 & 6,10 & 6,01 & 6,02 & 5,67 \\
\hline $\begin{array}{l}\text { C 18:1w12t } \\
\text { Petroselaidic }\end{array}$ & - & 0,15 & 0,15 & 0,14 \\
\hline $\begin{array}{l}\text { c11-C 18:1 } \\
\text { Vaccenic }\end{array}$ & 1,31 & 1,02 & 1,32 & 1,30 \\
\hline C 18:1w9c Oleic & 30,36 & 30,91 & 30,61 & 30,68 \\
\hline $9,12-\mathrm{t}, \mathrm{c}-\mathrm{C} 18: 2$ & 0,15 & 0,13 & - & 0,01 \\
\hline $\begin{array}{c}\text { C 18:2w6c } \\
\text { Linoleic }\end{array}$ & 37,42 & 37,47 & 37,27 & 37,88 \\
\hline C 20:0 & 0,15 & 0,15 & 0,15 & 0,15 \\
\hline C 20:1w9 & 0,07 & 0,07 & 0,07 & 0,07 \\
\hline C $20: 1 w 11$ & 0,30 & 0,31 & 0,30 & 0,30 \\
\hline C 18:3w6 & 0,23 & - & - & 0,19 \\
\hline $\begin{array}{l}\text { C 18:3w3 a- } \\
\text { Linolenic }\end{array}$ & 1,30 & 1,55 & 1,34 & 1,37 \\
\hline c9t11-C18:2 & 0,12 & 0,12 & 0,12 & - \\
\hline t10c12-C 18:2 & 0,01 & 0,01 & 0,01 & 0,01 \\
\hline 11,14 - с C 20:2 & 0,22 & 0,14 & 0,22 & 0,20 \\
\hline C 20:3w6 & 0,17 & 0,17 & 0,17 & 0,15 \\
\hline $\begin{array}{c}\text { C 20:4w6 } \\
\text { Arachidonic }\end{array}$ & 1,17 & 1,08 & 1,08 & 0,84 \\
\hline C $20: 5 w 3 c$ & 0,02 & 0,02 & 0,02 & 0,07 \\
\hline C $22: 0$ & 0,17 & 0,17 & 0,17 & 0,18 \\
\hline C 22:5w3 & 0,06 & 0,06 & 0,07 & 0,05 \\
\hline C 23:0 & - & - & - & 0,01 \\
\hline C 24:0 & 0,06 & 0,06 & 0,06 & 0,06 \\
\hline C 24:1 & 0,02 & - & - & - \\
\hline C 22:6w3 & - & - & - & 0,04 \\
\hline Total & 100,00 & 100,00 & 100,00 & 100,00 \\
\hline
\end{tabular}


Table 2

Biological parameters of fatty acids composition of investigated pastes, $\%$ of the sum of fatty acids

\begin{tabular}{|l|c|c|c|c|}
\hline \multirow{2}{*}{ Name } & \multicolumn{4}{|c|}{ Samples } \\
\cline { 2 - 5 } & Control & $\begin{array}{c}\text { No. 1 } \\
\text { "Mushroom" }\end{array}$ & $\begin{array}{c}\text { No. 2 } \\
\text { «Special» }\end{array}$ & $\begin{array}{c}\text { No. 3 } \\
\text { phytocomplex } \\
\text { "CHOICE" }\end{array}$ \\
\hline \multicolumn{5}{|c|}{ Value of groups of fatty acids } \\
\hline SFAs & 23,78 & 23,35 & 23,88 & 23,41 \\
\hline MUFAs & 35,46 & 34,74 & 35,79 & 35,82 \\
\hline PUFAs & 40,76 & 41,92 & 40,33 & 40,77 \\
\hline \multicolumn{5}{|c|}{ The content of essential acids } \\
\hline Linoleic C 18:2 & 37,42 & 37,47 & 37,27 & 37,88 \\
\hline Linolenic C 18:3 & 1,30 & 1,55 & 1,34 & 1,37 \\
\hline \multicolumn{5}{|c|}{ The content of anti-food fatty acids } \\
\hline C 18:1 trans & 0,16 & 0,15 & 0,15 & 0,14 \\
\hline C 18:2 trans & 0,02 & 0,03 & 0,02 & 0,02 \\
\hline
\end{tabular}

Analyzing the data in Table 2, it was found that the content of mono-unsaturated acids is about $35 \%$ and saturated - only $23 \%$ in all of the samples under study. This confirms the preventive effect of the developed pates, since from the point of view of the prevention of age-related diseases, the content of unsaturated fats should be as high as possible. Analyzing the content of PUFAs, it is important to note their stable high content in all four recipes, regardless of the type of ingredients added. However, the formula for "Mushroom" paste differs by the highest total content of PUFAs $-41.92 \%$ and at the same time the highest content of essential linolenic acid $-1.55 \%$. This, obviously, can be explained by the peculiarity of the fatty acid composition of the added additive, since fungi contain $1.3-2.7 \%$ fat, which $67 \%$ consists of polyunsaturated acids. It is established that the content of fatty acids in trans-form is insignificant and does not exceed their background level for all studied formulations [10].

In order to determine digestibility in conditions in vitro of the developed pates in comparison with the control sample, the relative biological value was determined in accordance with the guidelines for the use of the Tetrachymena pyriformis ciliary infusoria.

By the number of cultured infusion cells in the Fuks-Rosenthal chamber, the relative biological value of the product was established (Table 3).

Relative biological value of developed pates

Table 3

\begin{tabular}{|l|c|c|c|}
\hline \multicolumn{1}{|c|}{ Pastes } & $\begin{array}{c}\text { Protein, } \\
\mathbf{\%}\end{array}$ & $\begin{array}{c}\text { The number of } \\
\text { cells, cells } / \mathbf{~ m m}^{\mathbf{3}}\end{array}$ & $\begin{array}{c}\text { Relative biological } \\
\text { value* } \%\end{array}$ \\
\hline Control "To breakfast" & 20,24 & 185,85 & 52,864 \\
\hline Paste "Mushroom" & 20,16 & 198,45 & 56,448 \\
\hline $\begin{array}{l}\text { Paste with phytocomplex } \\
\text { "CHOICE" }\end{array}$ & 14,41 & 191,27 & 54,983 \\
\hline
\end{tabular}

* - in relation to the standard (casein) 
The analysis of the results obtained (Table 3) shows that "Mushroom" Paste has a higher relative biological value compared than the control sample more on $3.5 \%$, and the paste with the phyto-complex "CHOICE" more on $2.1 \%$. This means that in the mushroom pates and phyto-complex "CHOICE", the vital functions of the simplest cells are activated faster, and it contributes to the better digestibility of the product.

Meat products with high content of vitamin $\mathrm{B}_{12}$ have a health-preventive function, because cianocobalamin (vitamin $\mathrm{B}_{12}$ ) promotes increased non-specific resistance of the body to bacterial infection, has an immunomodulatory effect, based on the effect on the exchange of nucleic acids and proteins. Vitamin $\mathrm{B}_{12}$ deficiency is manifested by macrocytic hyperchromic anemia with characteristic bone marrow changes, neurological symptoms as a result of multiple lesions of the spinal cord. Investigation of the vitamin content of the researcher paste with mushroom raw material showed that the content of B12 is $-32.0 \pm 0.3$ $\mu \mathrm{g} / 100 \mathrm{~g}$, compared with the control $-24.5 \pm 0.2 \mu \mathrm{g} / 100 \mathrm{~g}$.

It has been established that the daily requirement of vitamin $B_{12}$ for the elderly is $2.4 \mu \mathrm{g}$ per day, since the level of fat-soluble vitamins and carotenoids in the plasma, as a rule, increases with age, with the exception of vitamin $\mathrm{D}$, while the level of water-soluble vitamins decreases, especially vitamins $\mathrm{B}_{6}$ and $\mathrm{B}_{12}$.

At the beginning of the medical biology study, we determined the level of vitamin B12 in the blood of patients. After conducting the necessary course of consumption of paste with mushroom raw material, a re-examination of patients was carried out to determine changes in vitamin $\mathrm{B}_{12}$ (cobalamin) indices in the blood. At the same time, they followed the change in the state of the human organism, from the consumption of the product.

Among the 15 people ( $65 \%$ of survey), the content of vitamin $\mathrm{B}_{12}$ in the blood was below $150 \mathrm{pg} / \mathrm{ml}$, with an average blood vitamin content of 139 (104-177) pg/ml, indicating a shortage of cobalamin in the elderly population. During the survey, it was found that the use of 50 grams of paste per day would provide 8 micrograms / day of vitamin in addition to the main diet, and if you consider that the average consumption of vitamin $\mathrm{B}_{12}$ with food in the examined patients was $5.8(4.6-9.1) \mu \mathrm{g} /$ day, the use of paste for 3 weeks will contribute to a significant increase in the content of vitamin $\mathrm{B}_{12}$ in the blood. Biochemical data showed that blood glucose, creatinine and uric acid levels did not change under the influence of the paste, but the decrease in urea was noted, due to the improvement of protein metabolism in the body under the influence of additional vitamin $\mathrm{B}_{12}$ intake and valuable protein (essential amino acids), since it is known that deficiency of vitamins and especially essential amino acids in elderly people leads to increased protein degradation and increased excretion of nitrogenous compounds.

\section{Conclusions}

According to the results of scientific research, meat pastes for health-preventive nutrition were obtained, in which the content of mono-unsaturated acids is about $35 \%$, and saturated - only $23 \%$. The formula with mushroom raw material has the highest total PUFAs content $-41.92 \%$ and at the same time the highest content of essential linolenic acid $-1.55 \%$.

The results of the study on the digestibility of developed pastes with the use of the Tetrahymena pyriformis ciliary infusoria in vitro indicate that the "Mushroom" "Mushroom" Paste has a higher relative biological value compared than the control sample more on $3.5 \%$, and the paste with the phyto-complex "CHOICE" more on $2.1 \%$. This means that in the mushroom pastes and phyto-complex "CHOICE", the vital functions of the simplest cells are activated faster, and it contributes to the better digestibility of the product. 
In the developed paste "Mushroom", vitamin $\mathrm{B}_{12}$ is found in an accessible form for human body of the elderly and is easily absorbed from the gastrointestinal tract into the blood, all patients well tolerated the ingestion of paste, no side effects were detected. The use of paste contributes not only to the elimination of vitamin $\mathrm{B}_{12}$ deficiency, but also significantly improves the biochemical parameters of albuminous and, especially, lipid metabolism in the elderly and may be recommended for inclusion in the diet as an additional source of vitamin $\mathrm{B}_{12}$ in order to improve the health status.

\section{References}

1. Gavalko G., Peshuk L, Sineok L., Romanenko M., Gashchuk A. (2015), Effect of gerodietic meat pate on biochemical parameters in the elderly: the role of vitamin $\mathrm{B}_{12}$, Advances in gerontology, 28(3), pp. 571-578.

2. Peshuk L., Gashchuk O., Moskalyuk O., Gagach I. (2014), Development of meat herodic products - a priority on scientific discipline, Visnyk of the Sumy National Agrarian University, 2/2(25), pp.187-190.

3. Moskalyuk O., Peshuk L., Gashchuk A., Chernyushok O. (2017), Development of meat pate of high biological value, Food industry: science and technology, 4(38), pp. 9-13.

4. Moskalyuk O., Gashchuk O., Peshuk L. (2017), Development of pates using phytocomplex of cereal crops "Choice", Naukovi pratsi NUHT, 23(4), pp. 238-243.

5. Jussi L. (2015), Enzymes of sprouted whet and their possible tehchnological significance, Paivi Kanerva, Chonggang Zhang, Tuula Sontag-Strohm, Chapman\&Hall, pp. 143-144.

6. Salovaara H., Michael G. (2016), Growth features of PbS crystals grown in silica gels, Journal of Crystal Growth, 6, pp. 214.

7. Mnerie D., Gaceu L., Gubenia O., Shamtsyan M., Birca A., Mnerie G.V. (2016), Comparative study on the evolution of the food labeling quality in some countries from the Black Sea Region, Journal of Hygienic Engineering and Design, 14, pp. 60-65

8. Kremena Nikovska, Galina Stefanova, Lyubomir Stefanov, Stanka Damyanova, Albena Stoyanova, Oleksii Gubenia (2018), Influence of adding of laurel essential oil extracts on salad dressings properties, Ukrainian Food Journal, 6(3), pp. 433-442

9. Knapp H. (2003), Physiologi calandbiochemicale ffectsof n-3 fattyasidsinma, Essential Fatty Acidsand Eicosanoids, AOCS Publications, pp. 330-333.

10. Clarke R., Lewington S. (2006), British Nutrition Foundationin formation sheetont rans-fattyacids, British Medical Journal, 333, pp. 214.

11. Telychkun V.I., Gavva O.M., Telychkun Yu.S., Gubenia O.O., Desyk M.H., Chepeliuk O.M. (2017), Tekhnolohichni kompleksy kharchovykh vyrobnytstv, Stal, Kyiv.

12. M. O'Keeffe (2005), Food and nutritional analysis | Meat and Meat Products, Encyclopedia of Analytical Science, Elsevier, pp. 302-312.

13. Tingting Liu, Nazimah Hamid, Kevin Kantono, Loveena Pereira, Scott O. Knowles (2016), Effects of meat addition on pasta structure, nutrition and in vitro digestibility, Food Chemistry, 213, pp. 108-114 